n.tronos

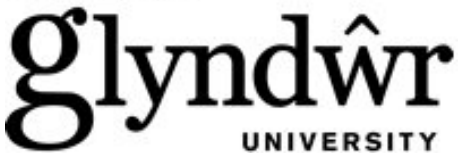

Glyndŵr University

Glyndŵr University Research Online

7-1-2012

\title{
Nanomagnetic domains of chromium deposited on vertically-aligned carbon nanotubes
}

\author{
Andrew C. Wright \\ Michael K. Faulkner \\ University of Manchester \\ Robert C. Harris \\ University of Leicester \\ Alex Goddard \\ University of Leicester \\ Andrew P. Abbott \\ University of Leicester
}

Glyndwr University, a.wright@glyndwr.ac.uk

Follow this and additional works at: http://epubs.glyndwr.ac.uk/amrl

Part of the Nanoscience and Nanotechnology Commons

\section{Recommended Citation}

Wright, A.C., Faulkner, M.K., Harris, R.C., Goddard, A., and Abbott, A.P. (2012) "Nanomagnetic domains of chromium deposited on vertically-aligned carbon nanotubes”. Journal of Magnetism and Magnetic Materials, 324, pp. 4170-4174 doi.org/10.1016/

j.jmmm.2012.07.044 available online 28th July 


\title{
Nanomagnetic domains of chromium deposited on vertically-aligned carbon nanotubes
}

\begin{abstract}
The drive to create ever smaller magnetic memory devices has led to the development of new nanomagnetic domains on surfaces. This paper reports the development of nano-chromium magnetic domains obtained using electrodeposition on vertically aligned carbon nanofibers arrays. Attempts to achieve this using conventional aqueous solutions were unsuccessful even after thin nickel underlayers were applied. The use of a novel electrolyte, a deep eutectic solvent, made from choline chloride: chromium (III) chloride enabled highly conformal overcoatings of chromium on individual bare carbon nanotubes to be obtained. Very high aspect ratio metal microstructures could be obtained by this novel technology. Magnetic imaging of the coated nanoarrays showed there to be clear magnetic character to the coating when the thin coatings were applied but this disappeared when the deposits were thicker and more contiguous.
\end{abstract}

\section{Keywords}

Nanomagnet, Carbon, Nanotube, Electrodeposition, Chromium

\section{Disciplines}

Nanoscience and Nanotechnology

\section{Comments}

Copyright (C) 2012 Published by Elsevier B.V. All rights reserved.

NOTICE: this is the author's version of a work that was accepted for publication in Journal of Magnetism and Magnetic Materials. Changes resulting from the publishing process, such as peer review, editing, corrections, structural formatting, and other quality control mechanisms may not be reflected in this document. Changes may have been made to this work since it was submitted for publication. A definitive version was subsequently published in Journal of Magnetism and Magnetic Materials, (2012) and is available at http://dx.doi.org/ 10.1016/j.jmmm.2012.07.044 on the publisher's website http://www.sciencedirect.com/ 


\title{
Nanomagnetic domains of chromium deposited on vertically-aligned carbon nanotubes
}

\author{
Andrew C. Wright ${ }^{a}$, Michael K Faulkner ${ }^{b}$, Robert C. Harris ${ }^{c}$ Alex Goddard $^{c}$ and Andrew P. Abbott $^{c}$ \\ *a Advanced Materials Research Laboratory, Materials Science Research Center, Glyndwr University, \\ Wrexham LL11 2AW, U.K. Fax +44(0)1978 293168; Tel: +44(0)1978 293369, \\ E-mail: a.wright@glyndwr.ac.uk \\ ${ }^{\mathrm{b}}$ Manchester Materials Science Centre, University of Manchester, Grosvenor Street, Manchester, \\ M13 9PL, UK, E-mail: m.faulkner@ manchester.ac.uk \\ ${ }^{c}$ Department of Chemistry, University of Leicester, Leicester, LE1 7RH, UK. E-mail: apa1 @le.ac.uk
}

*Corresponding author

\begin{abstract}
The drive to create ever smaller magnetic memory devices has led to the development of new nanomagnetic domains on surfaces. This paper reports the development of nano-chromium magnetic domains obtained using electrodeposition on vertically aligned carbon nanofibers arrays. Attempts to achieve this using conventional aqueous solutions were unsuccessful even after thin nickel underlayers were applied. The use of a novel electrolyte, a deep eutectic solvent, made from choline chloride: chromium (III) chloride enabled highly conformal overcoatings of chromium on individual bare carbon nanotubes to be obtained. Very high aspect ratio metal microstructures could be obtained by this novel technology. Magnetic imaging of the coated nanoarrays showed there to be clear magnetic character to the coating when the thin coatings were applied but this disappeared when the deposits were thicker and more contiguous.
\end{abstract}

Keywords: nanomagnet, carbon, nanotubes, electrodeposition, chromium 


\section{Introduction}

Vertically aligned carbon nanotubes (VA-CNTs) have become a popular subject for study since Ren $e t$ al. first reported their preparation using plasma-assisted chemical vapour deposition (PACVD) [1]. Since then, many research groups have investigated both the underlying science and applications of these novel materials which include field emission displays [2], cold cathodes for vacuum electronics [3], thermal management materials [4], and sensors [5] amongst many others. A recent review of potential applications demonstrates the high level of interest in these materials [6].

The high surface area of thin films of carbon nanotubes offers considerable potential for applications in energy storage, composites, new magnetic materials, catalysis and sensors. In the area of energy storage, interest in these materials for hydrogen storage by direct surface adsorption has waned although commercial success has been realized in lithium-ion batteries where bulk CNT fibers are used as an essential reinforcing agent in the electrode [7]. Without this reinforcement, battery life would be restricted to only a few cycles of charge/discharge making this battery technology practically unviable. Metal coated carbon nanotubes promise a route to metal matrix composites by mechanical consolidation and these materials have been shown to exhibit excellent wear resistance [8].

There has been increasing interest in the deposition of metals directly onto carbon nanotubes by chemical or electrochemical means, particularly for applications in composite materials [9-17]. Electrodeposition of nickel onto multi-walled nanotubes (MWNT), ultrasonically dispersed in standard Watt's bath has been described by An et al. [18]. Here the MWNT's were adsorbed onto a copper cathode where the nickel deposition takes place. Hence the characteristics of the cathode change with time as more MWNT's co-deposit with the nickel and are not the same as with a surface pre-coated with nanotubes. Xing et al. electroplated nickel from a simple chloride-only bath onto nanotube paper made from MWNT's and smooth deposits were obtained [19]. Overall, the aspect of metal coating carbon nanotubes by electrodeposition has so far been largely focused on nickel coatings and metal coating on high surface area templates deserves further exploration as a general technology. Metallic nanostructures have been previously realized using electrodeposition using liquid crystal templates [20] or self-assembled polymer nanospheres as templates [21]. At a more fundamental level, the electrochemistry of carbon nanotubes has been recently discussed by Dumitrescu et al. [22].

This paper reports the electrodeposition of chromium onto vertically aligned arrays of carbon nanotubes formed as thin films using PACVD. The industry standard chromic acid plating bath was 
replaced by a novel ionic liquid [23,24]. Abbott et al. showed that eutectic mixtures of choline chloride and $\mathrm{CrCl}_{3} \cdot 6 \mathrm{H}_{2} \mathrm{O}$ could be used for the deposition of chromium with much higher current efficiency, typically in excess of $90 \%$ [25]. The magnetic properties of chromium coated CNTs were examined using a magnetic force microscope and this showed that the nanoclustered deposits exhibited magnetic properties but these were lost when thick coatings were created.

\section{Experimental}

All CNT thin films were grown in a simple DC PACVD system based on a quartz bell jar very similar to that described elsewhere [26] operating at 8 mbar pressure using 50:200 sccm $\mathrm{C}_{2} \mathrm{H}_{2}: \mathrm{NH}_{3}$ flows at a temperature of $c . a .700^{\circ} \mathrm{C}$. Substrates for CNT growth included titanium nitride coated silicon chips or polished stainless steel. The CNT fibres had lengths of 5-7 $\mu \mathrm{m}$. Chromium electroplating was initially conducted with chromic acid $\left(250 \mathrm{~g} \mathrm{dm}^{-3} \mathrm{CrO}_{3}, 0.25 \mathrm{ml} \mathrm{H}_{2} \mathrm{SO}_{4}\right.$ with lead-silver alloy $(10 \% \mathrm{Ag})$ anodes) operated at $50^{\circ} \mathrm{C}$ [27]. A TTI EX4210R bench power supply was used with, currents of up to 10 Amps for chromium electroplating trials.

Chromium electrodeposition was carried out using a choline chloride and chromium chloride based ionic liquid (Cromline 200 from Scionix Ltd. UK) which was used as received. The deposition was conducted in an open beaker at $20^{\circ} \mathrm{C}$. Currents of no more than $0.15 \mathrm{~A}$ were used with a platinised titanium anode.

Nickel coatings as a smooth underlay prior to chromium deposition were obtained with a standard nickel sulfamate bath but with no additional additives [28]. The sulfamate bath composition was 30 $\mathrm{g} / \mathrm{L}$ of Boric acid, $315 \mathrm{~g} / \mathrm{L}$ nickel sulfamate and $1 \mathrm{~g} / \mathrm{L}$ nickel chloride $(\mathrm{pH} 4)$ and operated at $54{ }^{\circ} \mathrm{C}$. The nickel chloride is added to the sulfamate bath to maintain anode activity but is kept to a minimum to avoid internal stress in the deposit. Pure nickel anodes were used. A constant current of $10 \mathrm{~mA}$ was used for nickel plating. This is about one tenth of the normal current density for nickel plating of flat surfaces [28] when the total area of the carbon fiber is factored in. The carbon fiber arrays give an increase in surface area of some sixty-fold over the flat surface when fiber density, diameter and length are measured by SEM. Lower than standard current densities were used to ensure that plating occurred down at the fiber base and that the upper levels were not 'plated out' first. After electroplating, all samples were washed in water and then in iso-propyl alcohol before drying. The resulting electroplated microstructures were examined in a field-emission SEM (FEI XL30) at 12-15 kV. 
Atomic/Magnetic Force Microscope AFM/MFM images were acquired using a Digital Instruments (DI, Veeco) Nanoscope IV, Dimension 3100 instrument in resonant (tapping) mode (software version 6.12) and the designated quartz liquid-mode cantilever mount supplied directly by Veeco. The probe tip used to obtain these images was the MESP-RC model. The TM deflection images were acquired by passing the probe tip $40 \mathrm{~nm}$ above the sample to measure any magnetic response. All images were obtained at a scan rate of $0.600 \mathrm{~Hz}$.

\section{Results and discussion}

The electrodeposition of electronegative metals from aqueous solutions is notoriously inefficient. Chromium electrodeposition on fibrous carbon nano-tube materials proved very difficult to achieve using chromic acid baths because high currents were required to create deposits even onto the CNTfree areas of the chips. It is well known that electroplating using chromic acid is very inefficient, typically around $12 \%$, [27] with most the current being used for gas production. Negligible plating was observed on the CNT pads although some decoration around the pad was observed presumably due to insufficient current density in the CNT coated region. To circumvent this, an insulating ceramic coating (AREMCO Ceramabond 509) was applied to the chip edge and a pointed lead rod anode was employed to focus current towards the centre of the chip. Using this approach it was possible to successfully electroplate chromium using a constant current of $6 \mathrm{~A}$ for $30 \mathrm{~s}$. Figure 1a shows a typical SEM image of the deposit obtained under these conditions using chromic acid. The chromium deposits were formed as a dense crust rather than as a coating of each individual CNT. Using various current densities from 6A down to $0.15 \mathrm{~A}$ did not improve the nanotube coating and lower current densities than this did not result in material deposition. To improve on this result the CNTs were first individually coated with nickel using a standard nickel sulfamate bath (120 s at $10 \mathrm{~mA}, 1.2 \mathrm{C})$ before chromium plating. Figure 1b shows an SEM image of the nickel coated carbon nanotubes and it can clearly be seen that a conformal nickel coating is achieved. Repeating the chromic acid plating experiment with the Ni coated CNTs did not improve the deposition of chromium as can be seen from Figure 1c where strong clustering of the chromium at the nanotube ends has occurred.

Under these conditions some columnar growth was observed but the growths appear quite nodular in appearance and certainly much rougher than the nickel under-layer plated on the CNT fibers. The effect of a nickel underlay is however beneficial in that the chromium plating is now closer to conformal although still not ideal. 
Electrodeposition of chromium was subsequently carried out using a eutectic mixture of 1 choline chloride: $2 \mathrm{CrCl}_{3} \cdot 6 \mathrm{H}_{2} \mathrm{O}$. At this composition it is a dark green liquid with a viscosity of c.a. $2000 \mathrm{cP}$ and a conductivity of $<1 \mathrm{mS} \mathrm{cm}^{-1}$ at $30^{\circ} \mathrm{C}$ [23]. Previous reports have shown that black nanocrystalline deposits are electrodeposited from the eutectic mixtures, [24] however it has recently been reported that a different formulation can result in the deposition of thick, bright, adherent chromium with a hardness of 750 Vickers [25].

Using Chromeline 200 electroplating solution, bright chromium deposits were obtained using a current of $0.075 \mathrm{~A}$ for 10 minutes. The fibres are now encased in a thick chromium layer some 7-9 $\mu \mathrm{m}$ deep as shown in Figure 2. At higher currents still, $0.15 \mathrm{~A}$ for 10 mins, a very thick $\sim 20 \mu \mathrm{m}$ or so layer of chromium is formed. Ionic liquids commonly use much lower current densities to achieve metal deposition than aqueous solutions. Using a current of 0.018 A for 10 mins the deposit obtained was black in appearance. The much lower currents used with ionic liquid electrolytes meant that silicon substrates could be used which enabled the samples to be cleaved to expose the cross-sectional structure. Even at low currents, the chromium still has a tendency to be more concentrated near to the CNT pad edges and in this region the upper halves of fibers are conformally electroplated with chromium as shown in Figure 3a. The coating is much thinner on the lower portion of the deposit revealing small chromium clusters. Clearly the deposition process is limited by the depletion of chromium from the ionic liquid despite being present at a concentration of $2.9 \mathrm{~mol} \mathrm{\textrm {kg } ^ { - 1 }}$. Successful conformal over-plating over these very high aspect ratio structures requires that sufficiently high diffusion of chromium ions down to the fiber base must occur otherwise depletion will result in less metal being deposited there. The process of conformally overcoating such structures is then diffusion limited rather than kinetically limited. Higher currents will tend to 'plate out' the surface as more metal is being deposited there. Figure $3 b$ shows the center of the nanotube pad where current density is lower due to current crowding at the edges and this has clearly led to a thinner but uniform coating of chromium enabling a morphology which is more similar to that shown for nickel in Figure 1b.

These result obtained from the use of ionic liquid electrolytes are a considerable advance on that possible with chromic acid. The higher viscosities typical of ionic liquids (20-700 cP) [29] appear to be no obstacle to their use for high aspect ratio structures such as carbon nanotube forests.

Figure 4 shows the topography of three samples using an atomic force microscope. Figure 4 a shows 
the uncoated sample with a topography indicating clumping of nanotubes upon drying. The magnetisation profile was obtained by withdrawing the magnetic tip by $40 \mathrm{~nm}$ from the surface and then following the contours of the surface while measuring the magnetic force between the tip and the substrate. As would be expected the uncoated sample has no discernible magnetic character. A CNT array was coated with chromium by the same method as that described in Figure 3 using a current of 5 $\mathrm{mA}$ for 30 minutes. The topography shows that the coated nanotubes are clustered together which is seen to some extent in Figure $3 \mathrm{~b}$ but is commonly seen in other nanowire systems [30]. This is caused by the effect of surface tension or capillary forces upon drying and can result in cellular-like structures [31]. The magnetic force image shows a significant magnetic character which maps on to the chromium coated bundles as shown in Figure 4d. Coating the CNTs using a larger current but for a shorter time such that the total charge is roughly constant results in what is seemingly a similar topography (Figure 4e) but with no discernible magnetic character (Figure 4f). This is presumably because the chromium is not nano-dispersed (c.f. Figure $3 a$ ) and does not have the same magnetic character. The fact that some magnetic effect is seen on uncoated nanotubes can be ascribed to the very small nickel catalyst particle that is attached to end nanotube tip [1]. This effect disappears when covered with chromium.

Bulk chromium metal has the body centred cubic (BCC) structure and is an itinerant antiferromagnet that exhibits incommensurate spin density waves. Antiferromagnets such as bulk chromium have no net magnetic moment and are not expected to show contrast from magnetic-tip AFM. However, theoretical work has shown that small $(\mathrm{N} \leq 11)$ clusters of chromium exhibit a strong magnetic moment where $\mathrm{N}$ is an odd number of atoms [32,33]. Beyond a cluster size of 11, the structure begins to form the regular BCC form. Neutron diffraction studies of electrodeposited chromium have shown that crystal sizes can be as small as $27 \mathrm{~nm}$ [34]. Our results suggest that very thin chromium films as deposited on carbon nanotubes using ionic liquids contain very small chromium clusters which facilitate a finite magnetic moment able to be detected by magnetic-tip AFM.

We expect the magnetic chromium clusters to be surrounded by a thin layer of native oxide formed naturally on exposure to air. The initial electrodeposition will create larger clusters of chromium, most probably non-magnetic in character, which upon oxidation will result in a smaller number of chromium atoms able to exhibit a finite magnetic moment due to non-cancellation of spins. Repeated deposition/oxidation could in principle lead to the build up of a thicker magnetic layer. It is interesting that very recently there has been a report of switchable magnetic structures created with only twelve 
atoms of iron [35].

\section{Conclusions}

This work shows that it is possible to conformally electroplate chromium onto carbon nanotube arrays using commercially available ionic liquids based on choline chloride and chromium chloride. It is also shown that maintaining thin chromium coatings on the CNT arrays endows the coating with magnetic properties which could potentially be used for magnetic storage devices. It is shown that conformal chromium deposits are very difficult to achieve with the standard chromic acid bath composition even when smooth, thin nickel under-layers are used. The very low current efficiency of chromic acid baths leads to strong gas evolution which prevents the ingress of electrolyte into the fiber structure. The chromium based ionic liquid has a much higher current efficiency and circumvents many of the issues which arise with aqueous electroplating. It can be concluded that lower currents combined with longer times are beneficial to conformal over-plating using this technology. We show that it is possible to create thin film composites of chromium and carbon nanotubes which may have advantages for

tribological applications. Thin film composites of copper and ceramic particles have already been described using ionic liquids [36] and this study opens an alternative technique to preparing metal composite coatings.

\section{Acknowledgements}

This work was partly funded by the Welsh Assembly Governments Knowledge Exploitation Fund scheme 


\section{References}

[1] Z.F. Ren, Z.P. Huang, J.W. Xu, J.H. Wang, P. Bush, M.P. Siegal and P.N. Provencio, Synthesis of large arrays of well-aligned carbon nanotubes on glass, Science 282 (1998) 1105-1107.

[2] W.I. Milne, K.B.K. Teo, M. Chhowalla, G.A.J. Amaratunga, S.B. Lee, D.G. Hasko, H. Ahmed, O. Groening, P. Legagneux, L. Gangloff et al., Electrical and field emission investigation of individual carbon nanotubes from plasma enhanced chemical vapour deposition, Diamond and Related Materials, 12 (2003) 422-428.

[3] C. Bower, D. Shalóm, W. Zhu, D. López, G.P. Kochanski, P.L. Gammel and S. Jin, A micromachined vacuum triode using a carbon nanotube cold cathode, IEEE Trans. Electron Dev. 49 (2002) 1478-1483.

[4] Q. Ngo, B.A. Cruden, A.M. Cassell, G. Sims, M. Meyyappan, M.; J. Li and C.Y. Yang, Thermal interface properties of $\mathrm{Cu}$-filled vertically aligned carbon nanofiber arrays, Nano Lett. 4 (2004) 2403-2407.

[5] A. Modi, N. Koratkar, E. Lass, B. Wei and P.M. Ajayan, Miniaturized gas ionization sensors using carbon nanotubes, Nature 424 (2003) 171-174.

[6] M. Endo, M.S. Strano and P.M. Ajayan, Potential applications of carbon nanotubes, in: A. Jorio, G. Dresselhaus, M. S. Dresselhaus (Eds.), Carbon Nanotubes: Advanced Topics in the Synthesis, Structure, Properties and Applications, Topics in Applied Physics series vol. 111, SpringerVerlag Berlin/Heidelberg, 2008, pp. 13-61

[7] International Assessment of Research and Development of Carbon Nanotube Manufacturing and Applications. WTEC Panel Report June 2007. Http://www.wtec.org/cnm/CNM_final_report.pdf p 40 .

[8] L. Shi, C.F. Sun, P. Gao, F. Zhou, W.M. Liu, Electrodeposition and characterization of Ni-Cocarbon nanotubes composite coatings, Surf. Coat. Tech., 200 (2006) 4870-4875.

[9] Abe, Y.; Tomuro, R.; Sano, M. Highly efficient direct current electrodeposition of single-walled carbon nanotubes in anhydrous solvents, Adv. Mat. 17 (2005) 2192-2194.

[10] A. le Goff, V. Artero, B. Jousselme, P.D. Tran, N. Guillet, R. Metaye, A. Fihri, S. Palacin and M. Fontcave, From Hydrogenases to Noble Metal-Free Catalytic Nanomaterials for H(2) Production and Uptake, Science, 326 (2009) 1384-1387.

[11] A. Arai, M. Endo, S. Hashizume and Y. Shimojima, Nickel-coated carbon nanofibers prepared by electroless deposition, Electrochem. Commun. 6 (2004) 1029-1031. 
[12] H. Xing, L. Sun, G. Song, J. Gou and Y.W. Hao, Surface coating of carbon nanofibers/nanotubes by electrodeposition for multifunctionalization, Nanotech. 19 (2008) 025704.

[13] Y.C. Chen, R.J. Young, J.V. Macpherson and N.R. Wilson, Single-walled carbon nanotube networks decorated with silver nanoparticles: A novel graded SERS substrate, J. Phys. Chem. C, 111 (2007) 16167-16173.

[14] T.M Day, P.R. Unwin and J.V. Macpherson, Factors controlling the electrodeposition of metal nanoparticles on pristine single walled carbon nanotubes, Nano Lett., 7 (2007) 51-57.

[15] T.M. Day, P.R. Unwin, N.R. Wilson and J.V. Macpherson, Electrochemical templating of metal nanoparticles and nanowires on single-walled carbon nanotube networks, J. Am. Chem. Soc. 127 (2005) 10639-10647.

[16] K.Y. Lin, W.-T. Tsai, J.-K. and J.-K. Chang, Decorating carbon nanotubes with Ni particles using an electroless deposition technique for hydrogen storage applications, Int. J. Hydro. Energy, 35 (2010) 7555-7662.

[17] K.Y. Chun, Y. Oh, J. Rho, J.-H. Ahn, Y.-J. Kim, H.R. Choi and S. Baik, Highly conductive, printable and stretchable composite films of carbon nanotubes and silver, Nature Nanotech. 5 (2010) 853-857.

[18] B.G. An, L.X. Li and H.X. Li, Electrodeposition in the Ni-plating bath containing multi-walled carbon nanotubes, Mat. Chem. Phys. 110 (2008) 481-485.

[19] H. Xing, L. Sun, G. Song, J. Gou and Y.W. Hao, Surface coating of carbon nanofibers/nanotubes by electrodeposition for multifunctionalization, Nanotechnology 19 (2008) 025704.

[20] G.S. Attard, P.N. Bartlett, N.R.B. Coleman, J.M. Elliott, J.R. Owen and J.H. Wang, Mesoporous platinum films from lyotropic liquid crystalline phases, Science, 278 (1997) 838-840.

[21] P.N. Bartlett, P.R. Birkin and M.A. Ghanem, Electrochemical deposition of macroporous platinum, palladium and cobalt films using polystyrene latex sphere templates, Chem. Commun. 17 (2000) 1671-1672.

[22] I. Dumitrescu, P.R. Unwin and J.V. Macpherson, Electrochemistry at carbon nanotubes: perspective and issues, Chem. Commun. 45 (2009) 6886-6901.

[23] A.P. Abbott, G. Capper, D.L. Davies and R. Rasheed, Ionic liquid analogues formed from hydrated metal salts, Chem. Eur. J. 10 (2004) 3769-3774.

[24] A.P. Abbott, G. Capper, D.L. Davies, R.K. Rasheed, J. Archer, and C. John, Electrodeposition of chromium black from ionic liquids, Trans. Inst. Metal Finish, 82 (2004) 14-17. 
[25] E.L. Smith, C. Fullarton, R.C. Harris, S. Saleem, A.P. Abbott and K.S. Ryder, Metal finishing with ionic liquids: scale-up and pilot plants from IONMET consortium, Trans. Inst. Metal Finish 88 (2010) 285293.

[26] M. Chhowalla, K.B.K. Teo, C. Ducati, N.L. Rupersinghe, G.A.J. Amaratunga, A.C. Ferrari, D. Roy, D. Robertson and W.I. Milne, Growth process conditions of vertically aligned carbon nanotubes using plasma enhanced chemical vapor deposition, J. Appl. Phys. 90 (2001) 53085317.

[27] N.V. Mandich and D.L. Snyder, Electrodeposition of Chromium in Modern Electroplating, in: M. Schlesinger and M. Paunovic (Eds.) Modern Electroplating, $4^{\text {th }}$ edition, Wiley-Interscience, New York, 2000, pp. 289-360.

[28] G.A. Bari, Nickel Plating, in: F. Reidenbach, F. (Ed.) ASM Handbook, Vol .5 Surface Engineering, American Society for Materials, Metals Park Ohio, 8th Edition 1994, pp 201-212.

[29] H. Ohno, Physical Properties of ionic liquids for electrochemical applications, in: Endres F., A.P. Abbott and D.R. MacFarlane (Eds.) Electrodeposition from ionic liquids, Wiley-VCH Germany 2008, pp 54-78.

[30] S.Z. El Abedin and F. Endres, Free-Standing Aluminium Nanowire Architectures Made in an Ionic Liquid, ChemPhysChem 13 (2012) 250-255.

[31] N. Chakrapani, B. Wei, A. Carrillo, P.M. Ajayan and R.S. Kane, Capillarity-driven assembly of two-dimensional cellular carbon nanotube foams, Proc. Nat. Acad. Sci. 101 (2004) 4009-4012.

[32] H.S. Cheng and L.S. Wang, Dimer growth, structural transition, and antiferromagnetic ordering of small chromium clusters, Phys. Rev. Lett. 77 (1996) 51-54.

[33] Q. Wang, Q. Sum, B.K. Rao, P. Jena and Y. Kawazoe, Nitrogen-induced magnetic transition in small chromium clusters, J. Chem. Phys 119 (2003) 7124-7130.

[34] R. Przenioslo, J. Wagner, H. Natter, R. Hemplemann and W. Wagner, Studies of the fractal microstructure of nanocrystalline and amorphous chromium obtained by electrodeposition, $J$. Alloys and Compounds 328 (2001) 259-263.

[35] S. Loth, S. Baumann C.P. Lutz, D.M. Eigler and A.J. Heinrich, Bistability in Atomic-Scale Antiferromagnets, Science 335 (2012) 196-199.

[36] A.P. Abbott, K. El-Ttaib, G. Frish, K.J. McKenzie and K.S. Ryder, Electrodeposition of copper composites from deep eutectic solvents based on choline chloride., Phys. Chem. Chem. Phys. 11 (2009) 4269-4277. 



\section{Figure captions}

Figure 1: Chromium and Nickel electrodeposits on carbon nanotubes. Chromium electrodeposit obtained on bare nanotube fibers (1a) using chromic acid as the electrolyte after 60s at 6 A. Nickelcoated nanotube fibers (1b) as used as base template for chromium electrodeposition. Chromium coating deposited on nickel modified CNTs (1c) using chromic acid as the electrolyte after $376 \mathrm{~s}$ at a current of $10 \mathrm{~A}$.

Figure 2: Cross-sectional SEM image of chromium coated vertically aligned carbon nanotubes. Heavy chromium deposit obtained using a 1 choline chloride: $2 \mathrm{CrCl}_{3} \cdot 6 \mathrm{H}_{2} \mathrm{O}$ eutectic based ionic liquid using a current of $0.075 \mathrm{~A}$ for 10 minutes. Some individual protruding fibers are encased in thick chromium while lower levels of nanotube forest are totally embedded in metal.

Figure 3: Cross-sectional SEM images of chromium coated carbon nanotubes. Chromium electrodeposit from a 1:2 choline chloride: chromium chloride eutectic based ionic liquid on CNT. SEM image of the edge of grown forest showing smooth, conformally over-plated fibres in upper half (3a) and much thinner but uniformly over-plated fibers in centre of the forest pad ( $3 b)$. Current was $0.018 \mathrm{~A}$ for 10 minutes.

Figure 4: AFM topography of uncoated and chrome coated CNTs together with the magnetisation profile of the same area. Uncoated nanotubes are shown in 4a (topography) and $4 \mathrm{~b}$ (magnetisation). Nanotubes electroplated at $5 \mathrm{~mA}$ for 30 minutes show strong magnetic profile, $4 \mathrm{~d}$ with topography in 4c. Deposits created using higher currents (18mA) for shorter times (10 minutes) do not show magnetic profile, $4 \mathrm{f}$ while topography, $4 \mathrm{e}$, remains similar to $4 \mathrm{a}$ and $4 \mathrm{c}$. 
Figures

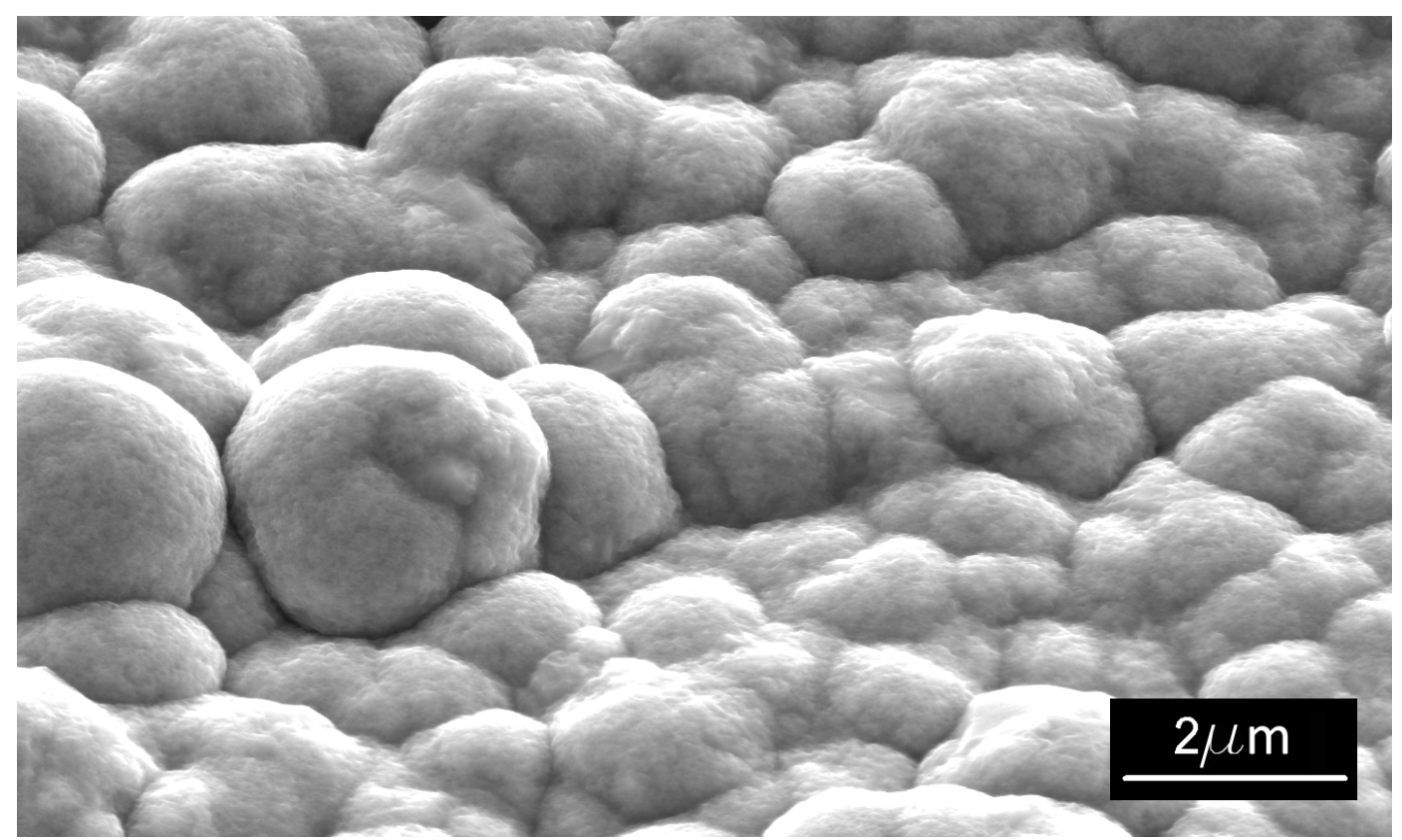

Figure 1a

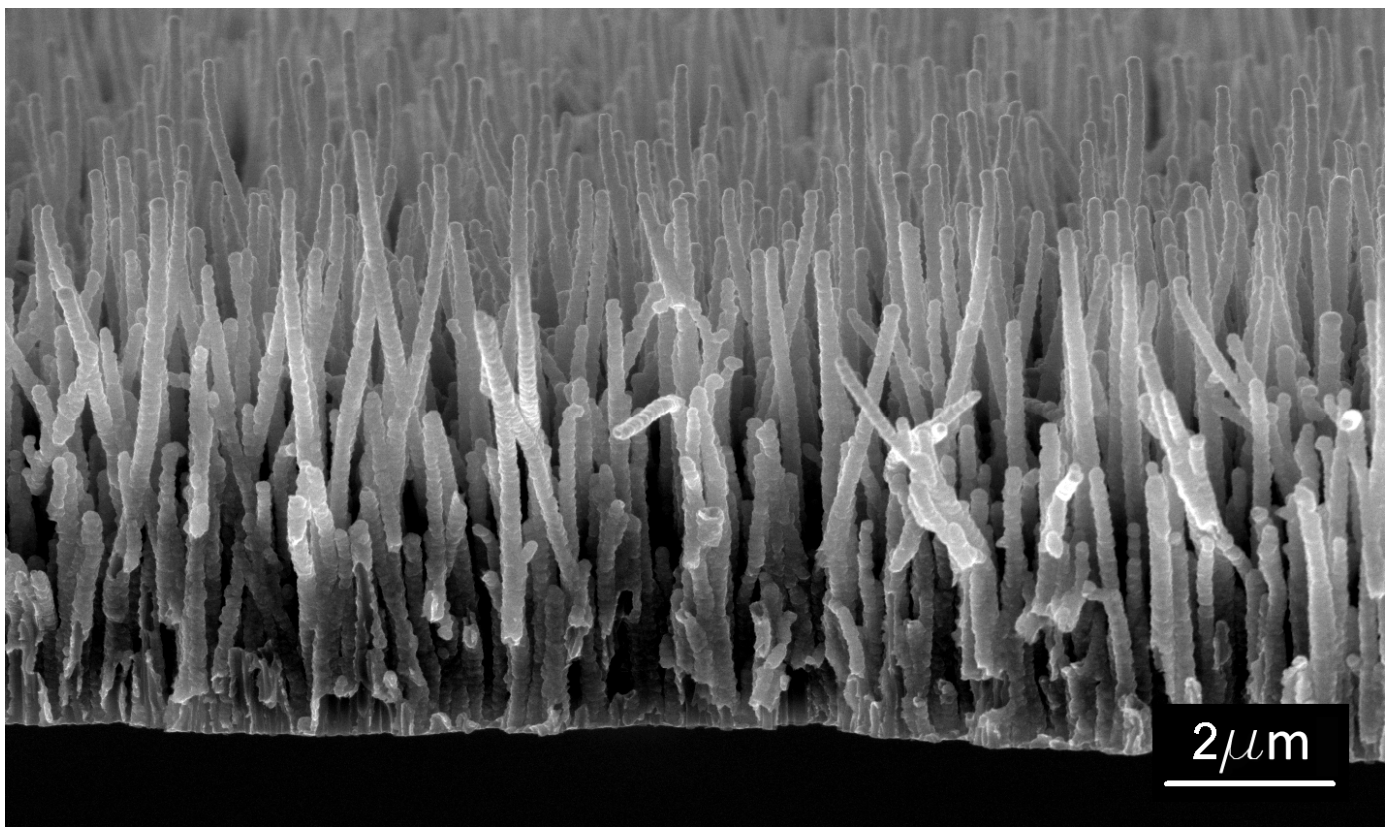

Figure 1b 


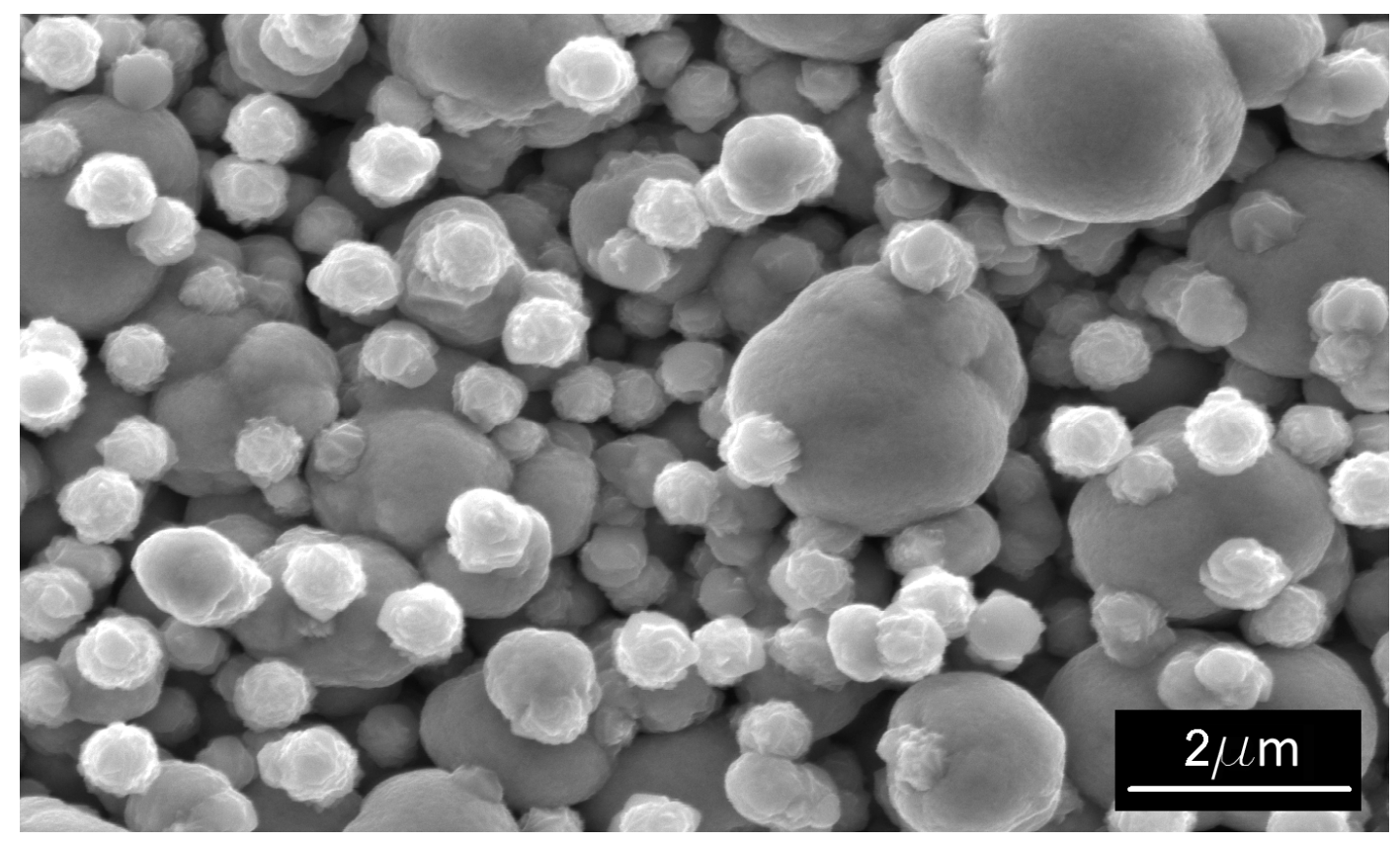

Figure 1c 


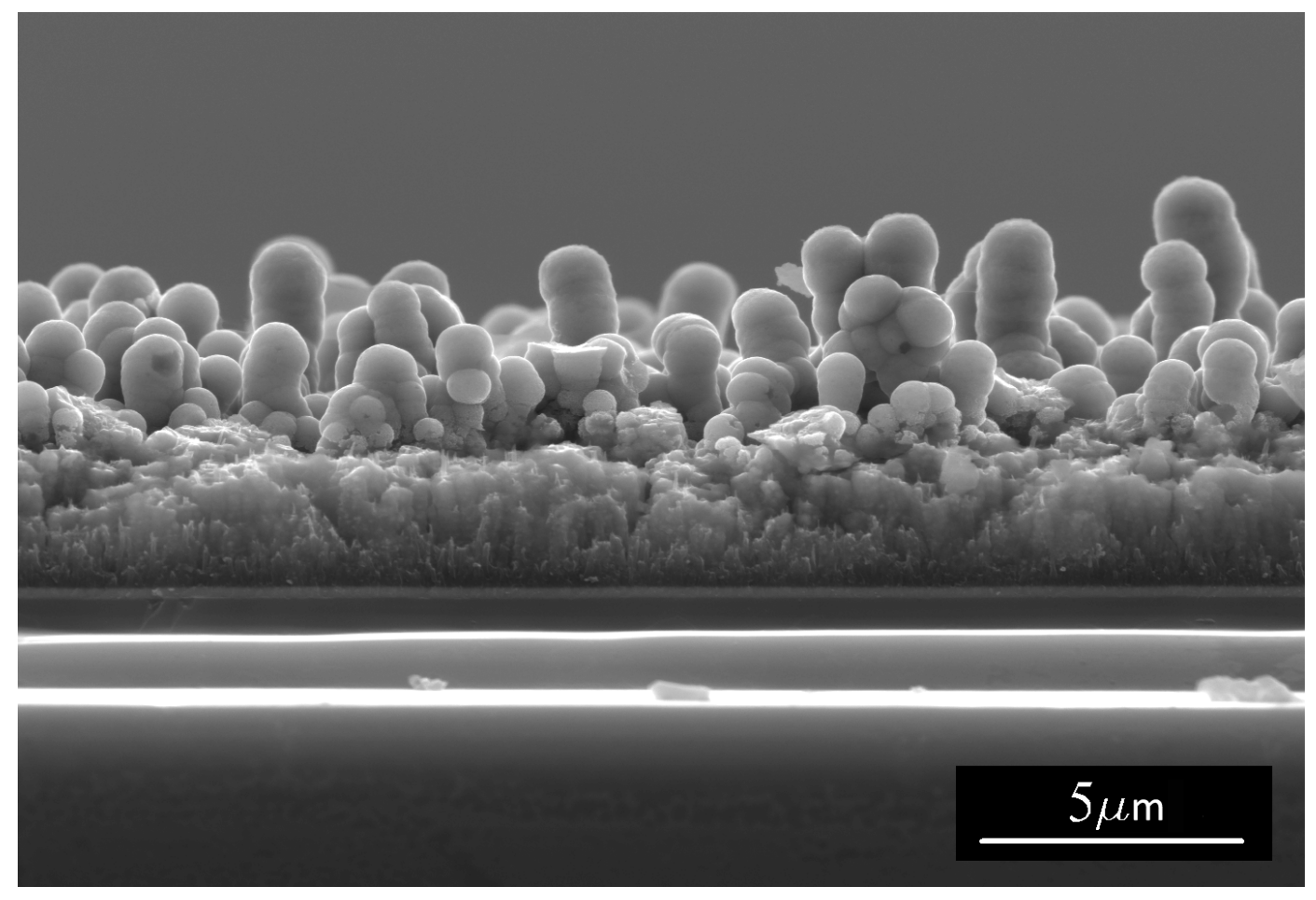

Figure 2 


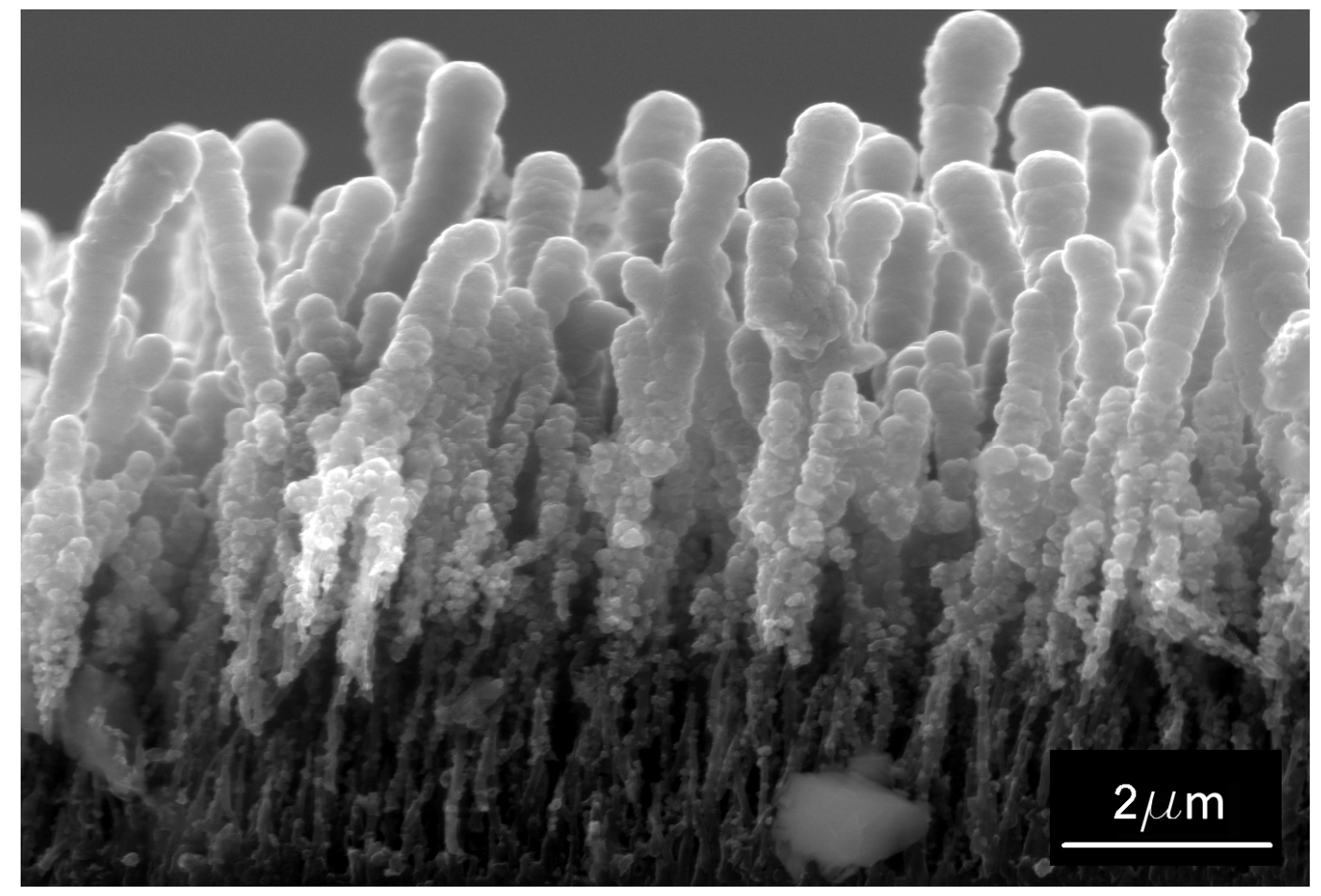

Figure 3a

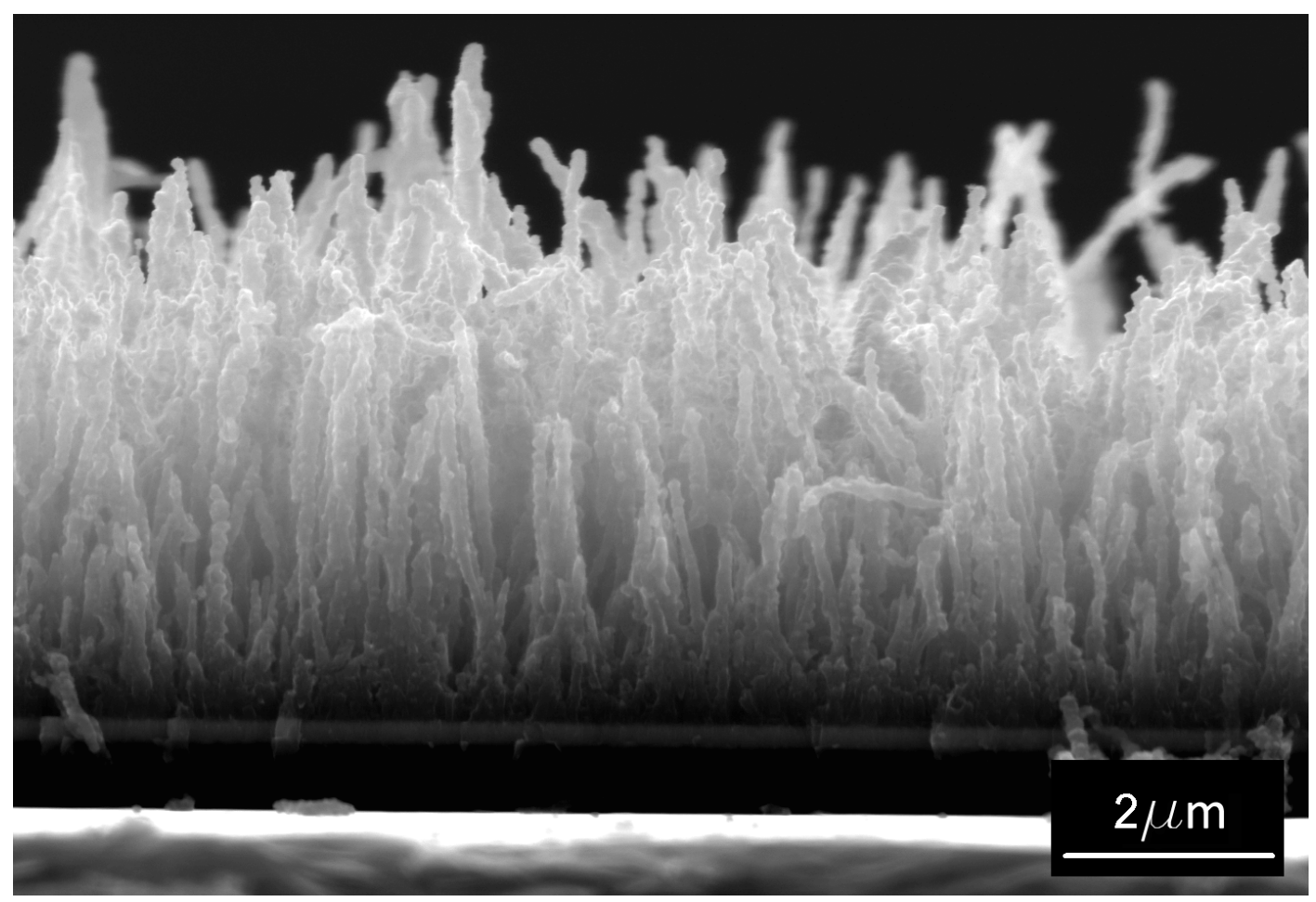

Figure $3 b$ 
Height Profile

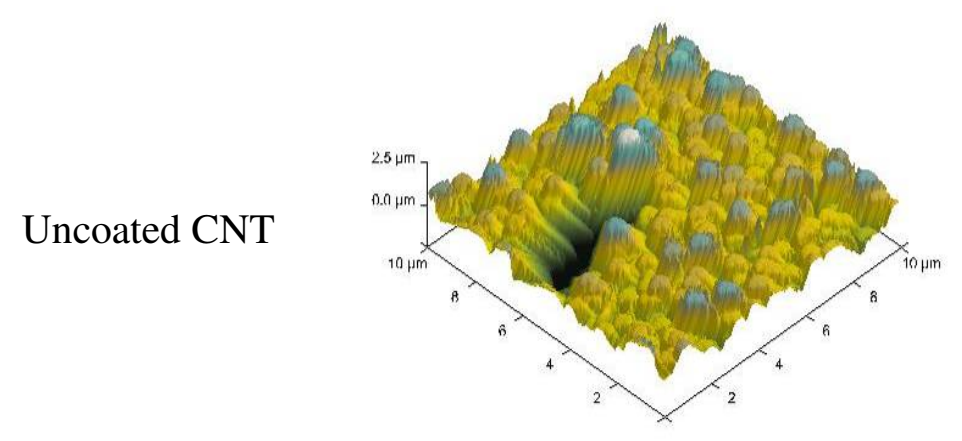

a

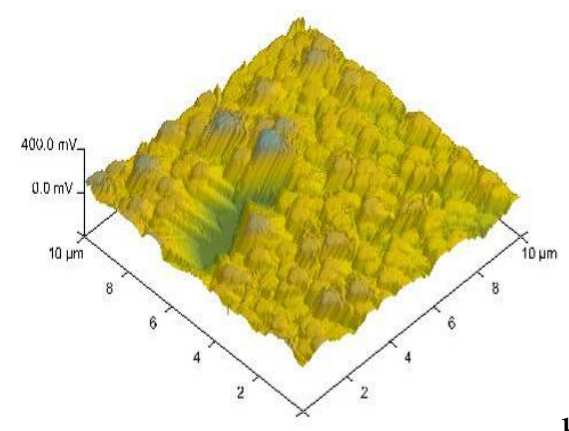

b

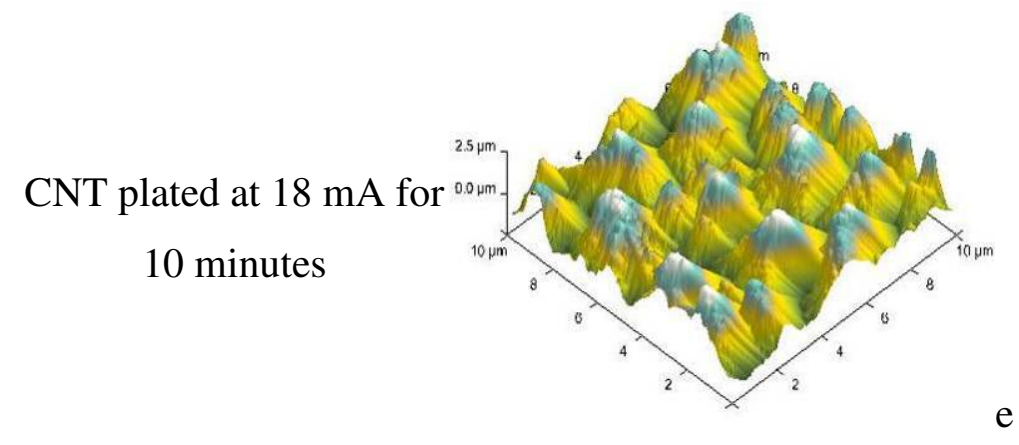

c
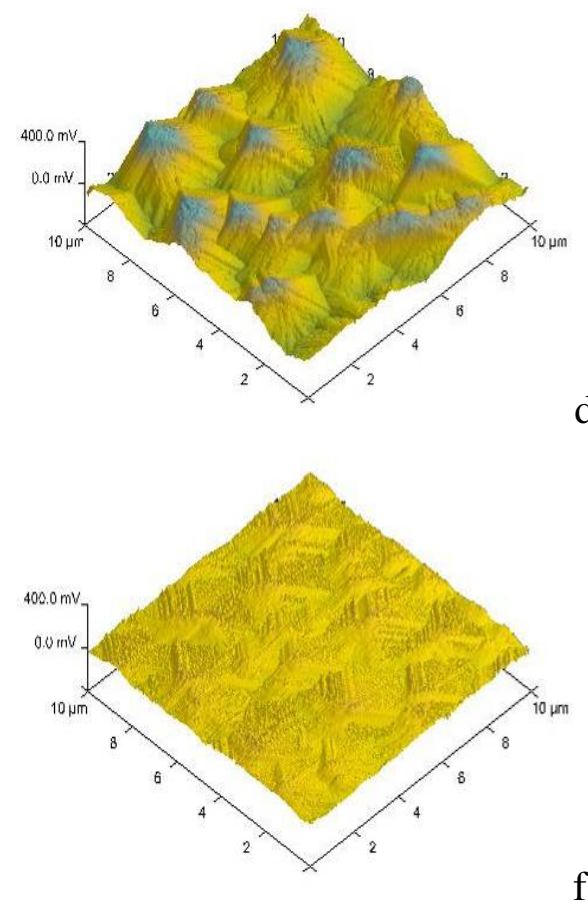

Figure 4 